\title{
SIMULTANEOUS DETERMINATION OF ACETAMINOPHEN AND TRAMADOL BY SECOND DERIVATIVE SPECTROPHOTOMETRY
}

\author{
M. INÉS TORAL (I)*, JORGE RIVAS ${ }^{(1)}$, MARTA SALDÍAS ${ }^{(1)}$, CÉSAR SOTO ${ }^{(2)}$, AND SANDRA ORELLANA ${ }^{(1)}$ \\ 1.- Department of Chemistry, Faculty of Sciences, University of Chile, P.O. Box 653, Santiago, Chile. \\ 2. - Department of Analytical and Inorganic Chemistry Faculty of Chemical Sciences \\ University of Concepción, P.O. Box 160C Concepción, Chile. \\ (Received: 4 September 2007 - Accepted: 25 February 2008)
}

\begin{abstract}
A rapid method for the simultaneous determination of acetaminophen $(\mathbf{A})$ and tramadol $(\mathbf{T})$ by second derivative spectrophotometric has been developed.

From a solvent effect studies and the spectral behaviours of $\mathbf{A}$ and $\mathbf{T}$, ethanol was selected as solvent. For a $\Delta \lambda$ value of $210 \mathrm{~nm}$ a smoothing factor of 8,000 and scale factor of 1,000,000 were selected, because in these conditions the signal/noise ratio was favoured in order to avoid error. In these conditions also it is possible the simultaneous determination of $\mathbf{A} / \mathbf{T}$ in a molar relation of $17 / 1$ contained in pharmaceutical formulations. At $285.7 \mathrm{~nm}$ the second derivative value is $\mathbf{T}$ concentration dependent, corresponding to zero-crossing point of A. On the other hand, T does not absorb between 296.0 to $400.0 \mathrm{~nm}$, thus $308.0 \mathrm{~nm}$ was selected for $\mathbf{A}$ determination by graphic method. The determination ranges for $\mathbf{A}$ and $\mathbf{T}$ were $8.1 \times 10^{-7}-51 \times 10^{-5} \mathrm{~mol} / \mathrm{L}$ and $3.4 \times 10^{-7}-5.0 \times 10^{-5} \mathrm{~mol} / \mathrm{L}$, respectively and can be determined with good precision and accuracy, without previous separation. A study of interferents, was carried out by using the excipients Zafin ${ }^{\circledR}$ tablet. The recoveries were $97.4 \pm 2.0 \%$ and $100.6 \pm 1.7 \%$ for $\mathbf{A}$ and $\mathbf{T}$, respectively. This tablet containing both drugs was assayed using the methods developed, showing a good accuracy and precision.
\end{abstract}

Keywords: Acetaminophen; Tramadol; Simultaneous Determination; Derivative Spectrophotometry; Pharmaceutical Formulation.

\section{INTRODUCTION}

Currently, one of the most important aspects in the pharmaceutical industry, it is to develop new pharmaceuticals formulation in order to reduce the pain and side effects. In this context, combinations of opioids and nonopioids have become important for the treatment in acute and chronic pain states $^{1}$. For these reasons a study of its effectiveness must be taken into account for the prescription of any analgesic ${ }^{2}$. On this respect, the monotherapy is one of the treatments usually made, whereby a pharmaceutical combination working by different ways it facilitates the treatment carrying out especially in old men chronic pain, clinical diagnostic and in extended treatments ${ }^{3}$.

In relation to their effectiveness and security, pharmaceutical formulations such as acetaminophen (A) and tramadol hydrochloride (T) are commonly used in the pain treatment, with the following combinations: $325 \mathrm{mg}$ of $\mathbf{A}$ with $37.5 \mathrm{mg}$ of $\mathbf{T}$, because of diverse clinical essays demonstrated that a synergy takes place, giving origin to another pharmaceutical formulations with more effectiveness that each drug for separate, diminishing the adverse effects of equivalent dose of $\mathbf{T}$ or $\mathbf{A}^{4,5}$.

The importance of this pharmaceutical combination has been demonstrated by the World Health Organization (WHO) analgesic scale in the level II pain treatment ${ }^{5}$. This combination is also used in patients when it is not possible to prescribe them nonsteroid anti-inflammatory, as previous step to the treatment with potent opioids and furthermore to spare the secondary effects of codeine or $\mathbf{T}$ that taken place in high dose or in extended treatments ${ }^{6,7}$.

On the other hand, this pharmaceutical combination it allows the symptomatic treatment of moderate, intense, acute and chronic pain, where effectiveness/side effects relation are high, whereby the dose of necessary $\mathbf{T}$ it is reduced to obtain an equivalent analgesic, as consequence the adverse effects are diminished and this composition became a fundamental pharmaceutical in the pain treatment.

Perrot et al. $2006{ }^{3}$ found that when the typical combination of $\mathbf{A} / \mathbf{T}$ contains a $25 \%$ less of $\mathbf{T}$, this has a similar analgesic effect in relation to the drugs given for separate. Further, when the amount of $\mathbf{T}$ in a $\mathbf{A} / \mathbf{T}$ combination is minor that a $25 \%$, the tolerance was improved in relation with the drugs prescribed for separate.

Nevertheless, Freeman R et al. $2007^{8}$ demonstrated that the combination $325 \mathrm{mg}$ of $\mathbf{A} / 37.5 \mathrm{mg}$ of $\mathbf{T}$ shows the effectiveness of $\mathbf{A} / \mathbf{T}$ in front of a placebo in painful diabetic peripheral neuropathy. Recent studies also, demonstrated that the supra-additive reduction of pain and hyperalgesia of the combination can result the more effective treatment strategies for different pain states containing both, acute nociceptor pain and hyperalgesia ${ }^{9}$.

In this context, it is necessary the development of an analytical method for the simultaneous determination of these drugs. On this respect, diverse methods have been reported for the $\mathbf{A}$ determination in pharmaceutical formulations and biological samples, individually or associated to other active compounds such as: UV /vis spectrophotometric, flow-injection analysis, multivariate, derivative, NIR, FTIR, chemiluminescence, electrochemicals, chromatographic methods, among others ${ }^{10}$. On the other hand, for the individual determination of $\mathbf{T}$ or associated to other drugs, different methods by chromatographic technique have been reported in pharmaceutical formulations and biological samples such as: high performance liquid chromatography (HPLC) coupled to different detectors, diode array ${ }^{11}, \mathrm{UV}^{12,13}$, fluorescence ${ }^{14,15}$ and electrochemical ${ }^{16}$, capillary gas chromatography ${ }^{17}$ and gas chromatography-mass spectrometry ${ }^{18-20}$, capillary electrophoresis ${ }^{21}$ and UV-vis spectrophotometry ${ }^{22}$ were also used for $\mathbf{T}$ determinations. Few attentions it has been put on simultaneous determination of $\mathbf{A}$ and $\mathbf{T}{ }^{23,24}$.

The aim of this work is to develop a simple, rapid, selective and low cost method for the simultaneous determination of $\mathbf{A}$ and $\mathbf{T}$ by derivative spectrophotometric technique. The proposed method was applied in pharmaceutical formulations.

\section{EXPERIMENTAL}

\section{Instruments}

A Shimadzu UV-1603 spectrophotometer with $10 \mathrm{~mm}$ quartz cells was used for absorbance measurement and derivative absorption spectra. For all the tested solutions, the second derivative spectra were recorded on the range between 190-400 $\mathrm{nm}$ against solvent, using $0.2 \mathrm{~nm}$ sampling intervals and scanning speed of $480 \mathrm{~nm} / \mathrm{min}$.

The spectral data were processed by software Shimadzu kit version 3.7 (P/N 206-60570-04). All solid samples were weighted with a $\pm 0.01 \mathrm{mg}$ of uncertainty using a Sartorius R 200D balance.

\section{Reagents}

All reagents were of analytical reagent grade. A (100.0\%) and T (99.7\%) were provided by Laboratorio Saval S.A., Santiago, Chile.

Stock solutions $1.0 \times 10^{-3} \mathrm{~mol} / \mathrm{L}$ of $\mathbf{A}$ and $\mathbf{T}$ were prepared dissolving 7.6 and $15.0 \mathrm{mg}$ of each compound respectively to $50 \mathrm{~mL}$ of ethanol as solvent. Other ranges of concentrations were prepared by appropriate dilution using the same solvent. The pharmaceutical product, Zafin ${ }^{\circledR}$ (Laboratorio Saval S.A., Santiago, Chile) containing both compounds was also dissolved using the same solvent. Furthermore, in order to carry out a study of the solvent effects on the spectral behaviour, stock solutions $1.0 \times 10^{-3} \mathrm{~mol} / \mathrm{L}$ of $\mathbf{A}$ and $\mathbf{T}$ were prepared by dissolving the amount previously described for each drug in different solvents. Other concentration ranges, were prepared by appropriate dilution using the respective solvent.

\section{Procedures}

Calibration graphs for determination of $\boldsymbol{A}$ and $\boldsymbol{T}$.

$\mathbf{A}$ and $\mathbf{T}$ aliquots of the stock solution were simultaneously diluted in ethanol in a concentration range between $1.0 \times 10^{-5}-6.0 \times 10^{-4} \mathrm{~mol} / \mathrm{L}$ and 1.0 x $10^{-5}-10.0 \times 10^{-5} \mathrm{~mol} / \mathrm{L}$ for $\mathbf{A}$ and $\mathbf{T}$, respectively. The calibration procedure was carried out in each compound in presence of $1.0 \times 10^{-5} \mathrm{~mol} / \mathrm{L}$ for $\mathbf{T}$ and $34.0 \times 10^{-5} \mathrm{~mol} / \mathrm{L}$ for $\mathbf{A}$. In all cases the corresponding absolute values of the 
second derivative spectra at $308.0 \mathrm{~nm}$ for $\mathbf{A}$ and $285.7 \mathrm{~nm}$ for $\mathbf{T}$ were obtained and plotted against the corresponding concentrations.

Simultaneous determination of $\boldsymbol{A}$ and $\boldsymbol{T}$ in mixtures with different mass ratios.

Stock solutions of each compound were prepared in ethanol and appropriately diluted to solutions containing mass ratios between $1 / 17$ and $3 / 51$. For each solution five repetitions were made. The second derivative spectra were evaluated and the concentration of each compound calculated to obtain both recovery values and relative standard deviation (RSD).

Photo-stability studies of $\boldsymbol{A}$ and $\boldsymbol{T}$.

A and T mixture stock solutions containing $2.0 \times 10^{-5}$ and $34.0 \times 10^{-5} \mathrm{~mol} / \mathrm{L}$ in ethanol were used in photo-stability studies. The individual solutions were exposed to direct light, indirect light and darkness between 30 min and $5 \mathrm{~h}$. The different solutions were evaluated each $30 \mathrm{~min}$ by second derivative spectra. Each solution was also evaluated to 24 and $48 \mathrm{~h}$.

Simultaneous determination of $\boldsymbol{A}$ and $\boldsymbol{T}$ in pharmaceutical formulations (tablets).

The content of 10 tablets of Zafin ${ }^{\circledR}$ (Laboratorio Saval S.A. Santiago, Chile) were weighted and powdered. A quantity of $10.64 \pm 0.01 \mathrm{mg}$ of powder was weighted and diluted in $50 \mathrm{~mL}$ of ethanol. The solution was shaken $20 \mathrm{~min}$, centrifuged and $1.7 \mathrm{~mL}$ from supernatant was diluted with ethanol to $10 \mathrm{~mL}$ and then was evaluated by second derivative spectrophotometry.

\section{RESULTS AND DISCUSSION}

The structures of these drugs are shown in Figure 1, both drugs are soluble in water and polar solvents. The spectral behaviours of $\mathbf{A}$ and $\mathbf{T}$ in a concentration range between $2.0 \times 10^{-5}$ to $8.0 \times 10^{-5} \mathrm{~mol} / \mathrm{L}$ were studied in different solvents. The better signal was found with the following solvent: water, ethanol and methanol, the last solvent is very volatile and was discarded. However, the pharmaceutical formulation contains an $\mathbf{A} / \mathbf{T}$ relation, which corresponds to 8/1 and $17 / 1$ in mass and molar ratio, respectively. It was necessary to carry out a spectral behaviour exhaustive study using water and ethanol as solvent.

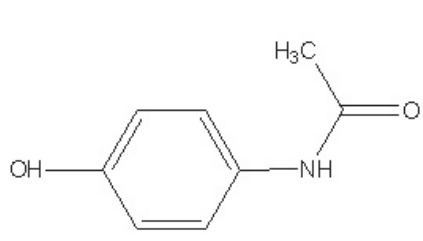

Acetaminophen (A)

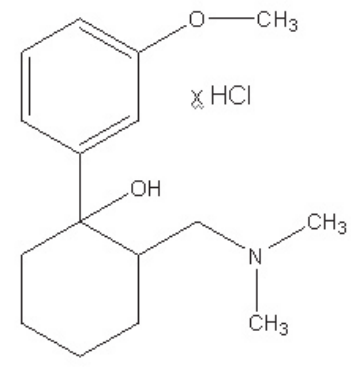

Tramadol hydrochloride (T) (T).

Figure 1: Structure of acetaminophen (A) and tramadol hydrochloride

In order to establish the photo-stability of $\mathrm{A}$ and $\mathbf{T}$ in ethanol, solutions containing $2.0 \times 10^{-5} \mathrm{~mol} / \mathrm{L}$ of $\mathbf{A}$ and $34.0 \times 10^{-5} \mathrm{~mol} / \mathrm{L}$ of $\mathbf{T}$ were exposed to direct light, indirect light and darkness. In all cases, photochemical degradation was not evidenced because the analytical signals remain constant.

Spectral behaviour

In the zero order spectra using equal concentrations of both drugs shown in Figure 2, A presents three maxima absorption band centred in 197.7, 248.6 and $294.0 \mathrm{~nm}$ and the absorption bands of $\mathbf{T}$ are centred in 199.6, $276.6 \mathrm{~nm}$, and a shoulder at $222.2 \mathrm{~nm}$. The most intense bands for both drugs are near UV-vacuum and totally overlapping, whereby this zone was discarded for the solvent studies. On the other hand, considering the $\mathbf{A} / \mathbf{T}$ molar and the absorbance ratios between 228.0 and $260.0 \mathrm{~nm}$, this range was discarded because the absorbance difference is very high for to develop a good method for this system.

Over $260.0 \mathrm{~nm}$ the absorbance are similar, in this condition it is possible to determine $\mathbf{A}$ in presence of $\mathbf{T}$, but it is not possible the $\mathbf{T}$ direct determination by this type of spectrophotometry because of the spectra are overlapped, whereby the derivative spectrophotometry was adopted for this simultaneous determination in a range between 260.0 to $340.0 \mathrm{~nm}$. According to the results this study was carried out with water and ethanol as solvents.
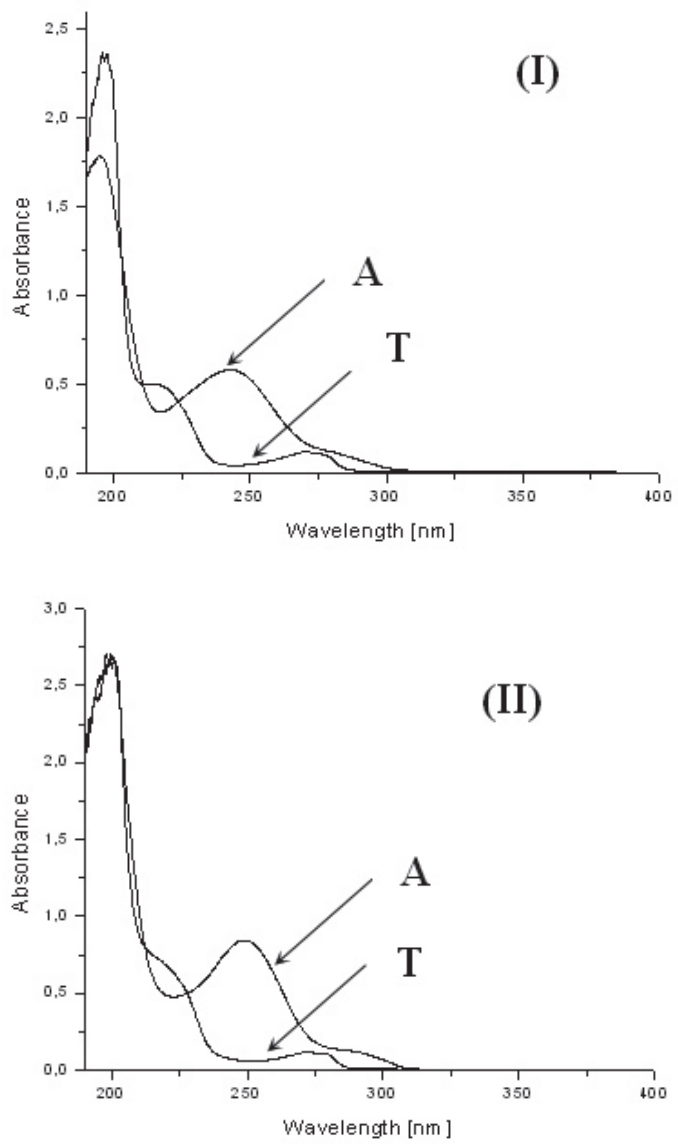

Figure 2: Classic spectrum of $\mathbf{A}$ and T. Concentration of $\mathbf{A}$ and $\mathbf{T}$ : $6.0 \mathrm{x}$ $10^{-5} \mathrm{~mol} / \mathrm{L}$. (I) Water and (II) Ethanol.

Selection of derivative order

In this work was used the digital derivative spectrophotometry based in Savitzky and Golay mathematical approach ${ }^{25}$. In this computational method the noise from derivative spectra is removal. In this differentiation way, the resolution is sacrificed in order to increase the signal/noise ratio.

For to optimise the derivative order, the first to fourth derivative spectra of the solution containing separately the respective drugs and using water and ethanol as solvent were recorded. Comparing the obtained derivative spectra, the first derivative (Figure 3) presents in both solvents the higher sensitivities, but it does not present a characteristic zone for each compound.

In the second derivatives (Figure 4) decrease the sensitivities in both solvent, nevertheless present a good resolution for this simultaneous determination. In this context, the second derivative was selected favouring the accuracy of the results and the precision of the method. Higher derivative orders were discarded because the sensitivities decrease and the signal/noise ratios also decrease. 
(I)

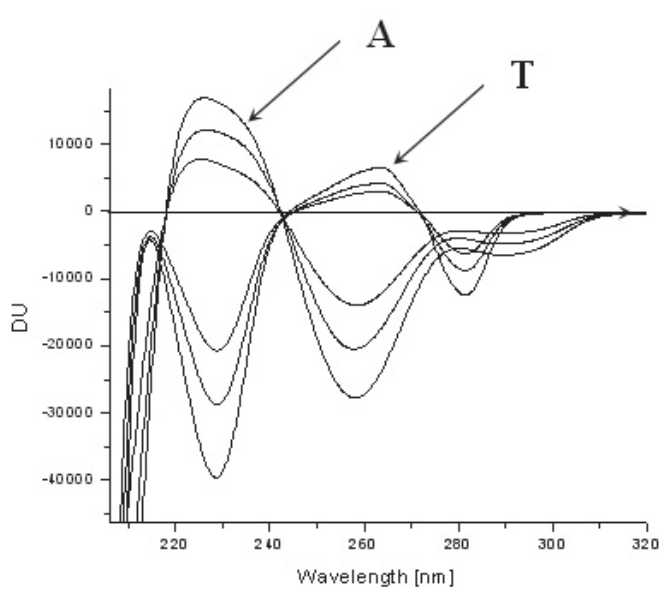

(II)

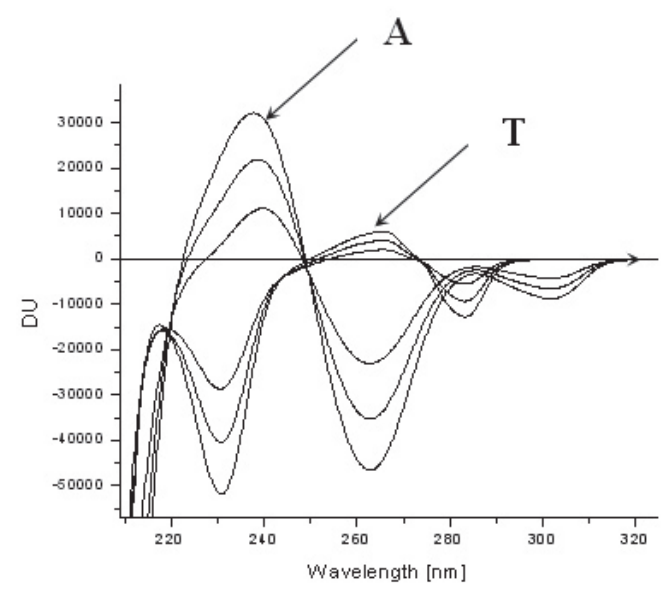

Figure 3: Zoom of the first derivative of $\mathbf{A}$ and T. Concentrations of $\mathbf{A}$ and T: $4.0 \times 10^{-5} ; 6.0 \times 10^{-5}$ and $8.0 \times 10^{-5} \mathrm{~mol} / \mathrm{L}$. (I) Water and (II) Ethanol.

In both solvents the drugs present similar results; however in water A presents a zero crossing but the $\mathbf{T}$ signal is very low (Figure $4 \mathrm{I}$ ). When ethanol was used the A presents also a zero crossing, however the $\mathbf{T}$ signal is very higher (Figure $4 \mathrm{II}$ ), under this condition is possible to work with higher concentrations of $\mathbf{A}$ in relation to $\mathbf{T}$, this situation is presented in pharmaceutical formulation sample. For these reasons, ethanol was selected as solvent.
(I)

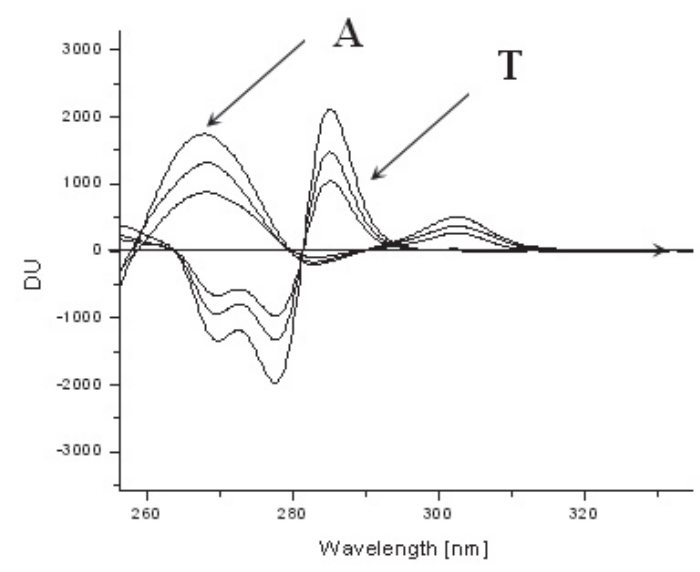

(II)

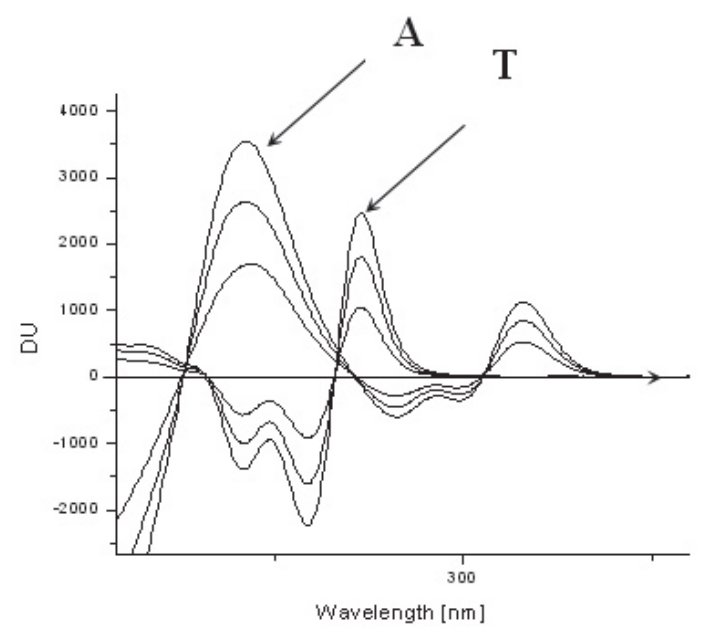

Figure 4: Zoom of the second derivative of $\mathbf{A}$ and $\mathbf{T}$. Concentrations of $\mathbf{A}$ and T: $4.0 \times 10^{-5} ; 6.0 \times 10^{-5}$ and $8.0 \times 10^{-5} \mathrm{~mol} / \mathrm{L}$. (I) Water and (II) Ethanol.

\section{Selection of spectral parameters}

In ethanol the second derivative spectrum of $\mathbf{T}$ in a wavelength range between 296.0 to $400.0 \mathrm{~nm}$ this drug does not absorb, when both drugs are presents the absorption is attributed to $\mathbf{A}$. The value of $308.0 \mathrm{~nm}$ was selected for the A determination because its signals are higher. On the other hand, $\mathbf{A}$ presents a zero crossing at $285.7 \mathrm{~nm}$, for this reason it was selected for the $\mathbf{T}$ determination. The second derivatives, using a value of 8,000 as smoothing factor and 10,000; 100,000 and 1,000,000 as scale factor were recorded, the last value was selected. It was possible to use this parameter for to improve the lecture of the analytical signal. The bands do not present distortions effect when the signals were amplified (Figures 5 I, 5 II and 5 III).

The compounds concentration effects on absorbance at analytic wavelengths were studied in similar concentration ranges to pharmaceutical formulations sample. The second derivative spectra of one drug at different concentrations in the presence of the other were recorded (Figure 6). These results confirm that the wavelengths previously selected can be used with analytical purposed, because isosbestic points and good linearity are observed and showing no mutual interference (Figures 6 I and 6 II).

Analytical features

Calibration graphs were obtained by plotting the derivative units (DU) versus analyte concentration of the second derivative spectra. The DU for $\mathbf{A}$ and $\mathrm{DU} \mathrm{U}_{(2.285 .7 \mathrm{~mm})}$ for $\mathbf{T}$, using a smoothing factor of 8,000, a scale factor of 
$1,000,000$ and a $\Delta \lambda$ of $210.0 \mathrm{~nm}$, versus the respective drugs concentrations. The equations for the $\mathbf{A}$ and $\mathbf{T}$ determination obtained by the least squares method are shown in Table 1.
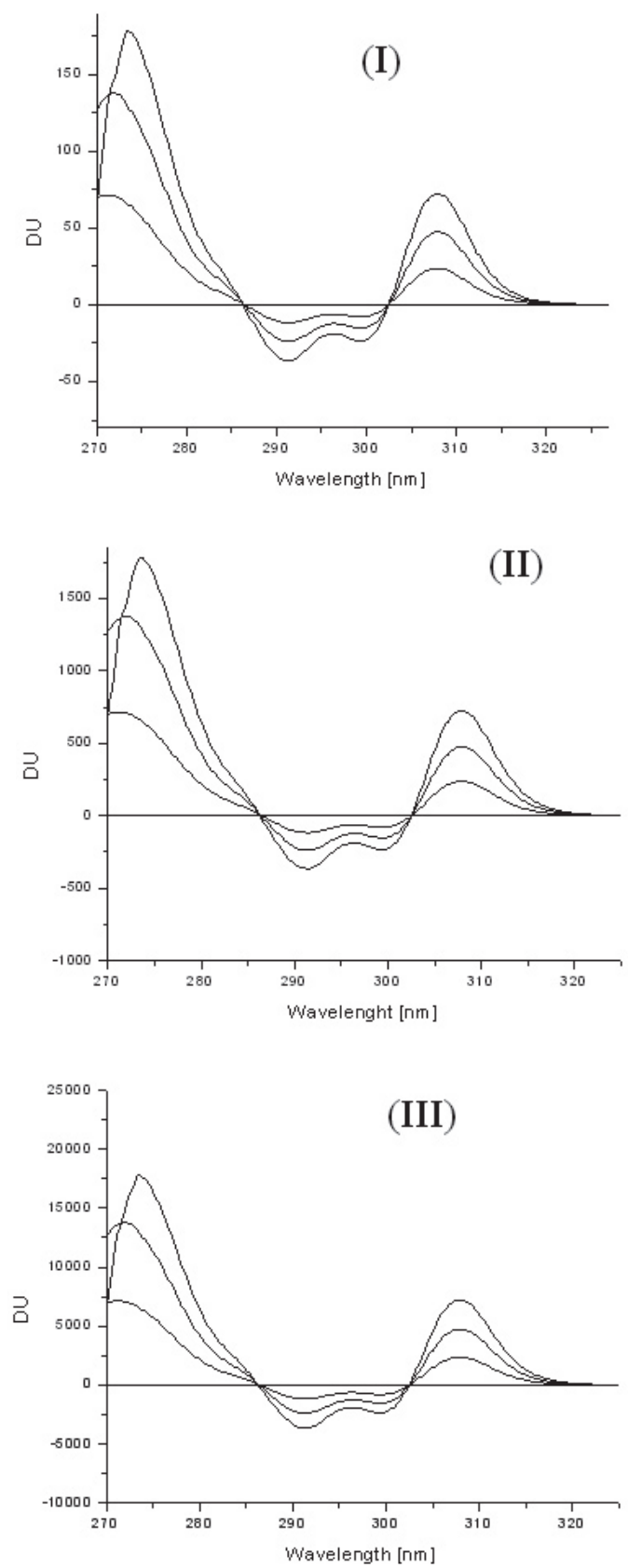

Figure 5: Zoom of effect of scale factor on second derivative in mixtures with different molar ratios of $\mathbf{A} / \mathbf{T}: 17 / 1,34 / 2$, and 51/3. Scale factor (I) 10,000 , (II) 100,000 and (III) $1,000,000$.

The detection and quantification limits were obtained by using the criteria given by ICH Harmonized Tripartite Guideline ${ }^{26}$. The following equations were used: $3.3 \sigma / \mathrm{S}$ and $10 \sigma / \mathrm{S}$, respectively, where $\mathrm{S}$ is the slope of the calibration curve and $\sigma$ is the standard deviation corresponding to the response of 11 independent blanks.
(I)

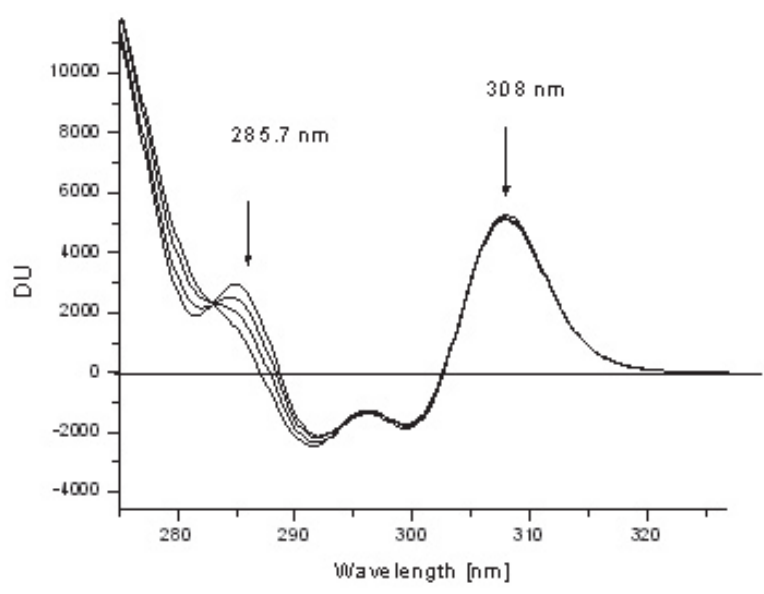

(II)

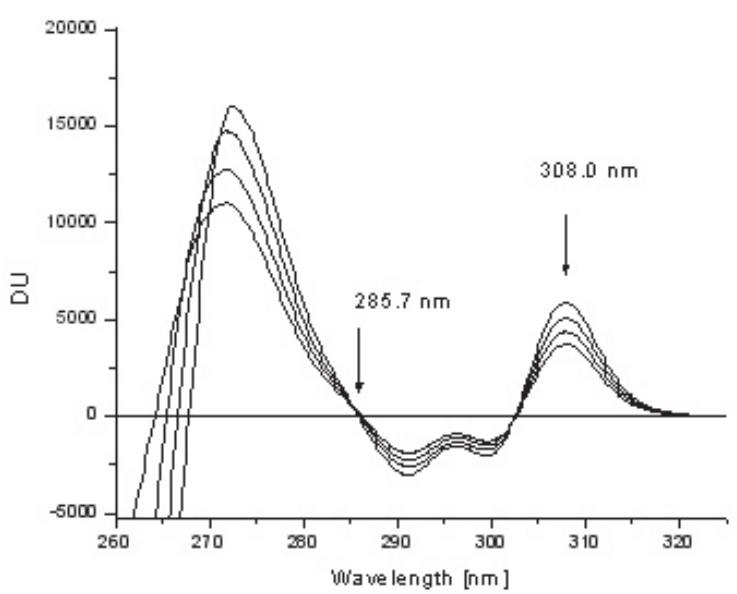

Figure 6: Zoom of the second derivative in ethanol of a drug where the concentration is variable in presence of the other constant. (I) $\mathbf{T}$ variable and A constant. Concentrations of T: $3.0 \times 10^{-5}, 5.0 \times 10^{-5}, 7.0 \times 10^{-5}$ and $9.0 \times 10^{-5}$ $\mathrm{mol} / \mathrm{L}$ in presence of $34.0 \times 10^{-5} \mathrm{~mol} / \mathrm{L}$ of $\mathbf{A}$. (II) A variable and $\mathbf{T}$ constant. Concentrations of A: $25.0 \times 10^{-5}, 30.0 \times 10^{-5}, 35.0 \times 10^{-5}$ and $40.0 \times 10^{-5} \mathrm{~mol} / \mathrm{L}$ in presence of $1.0 \times 10^{-5} \mathrm{~mol} / \mathrm{L}$ of $\mathbf{T}$.

According to same criteria, the repeatability was obtained by using standards samples containing $17.0 \times 10^{-5}$ and $1.0 \times 10^{-5} \mathrm{~mol} / \mathrm{L} ; 34.0 \times 10^{-5}$ and $2.0 \times 10^{-5} \mathrm{~mol} / \mathrm{L} ; 51.0 \times 10^{-5}$ and $3.0 \times 10^{-5} \mathrm{~mol} / \mathrm{L}$ of $\mathbf{A}$ and $\mathbf{T}$, respectively. For each mixture 3 replicates were carried out. The repeatability, expressed as relative standard deviation (RSD), was obtained using the standard deviation and average of the concentration of the 9 standards samples used in this determination. The determination range was defined between the quantification limit and the loss of linearity; obtaining a high linearity degree with accuracy and precision in the results when the proposed method was applied. The summarized results obtained are shown in Table 1. 
Table 1. Analytical features

\begin{tabular}{|c|c|c|}
\hline Analytical parameters & Acetaminophen & Tramadol \\
\hline & & $1.0 \times 10^{-7}$ \\
\hline Detection limit (mol/L) & $2.4 \times 10^{-7}$ & $3.4 \times 10^{-7}$ \\
\hline $\begin{array}{c}\text { Quantification limit (mol/L) } \\
\text { Determination range } \\
(\text { mol/L) }\end{array}$ & $8.1 \times 10^{-7}$ & $3.4 \times 10^{-7}-5.0 \times 10^{-5}$ \\
\hline Repeatability $(\mathrm{RSD}, \%)$ & 1.17 & 0.78 \\
\hline Linear Regression & $\mathrm{DU}=1.5 \times 10^{7} \mathrm{C}-4.3$ & $\mathrm{DU}=2.3 \times 10^{-5} \mathrm{C}+28.7$ \\
\hline Correlation coefficient & 0.999 & 0.999 \\
\hline
\end{tabular}
in $\mathrm{mol} / \mathrm{L}$.

${ }^{\text {a }}$ Where DU corresponds to derivative units, and C to analyte concentration

In order to establish the ratios at which $\mathbf{T}$ can be accurately measured in presence of high concentrations of $\mathbf{A}$, the recoveries of analyte in synthetic samples containing standard solutions of $\mathbf{A}$ and $\mathbf{T}$ in different concentration ratio were carried out (Table 2). Taking into account these results, it is possible to conclude that this method permits the simultaneous determination of $\mathbf{A}$ and $\mathbf{T}$ in pharmaceutical formulations where $\mathbf{A}$ has a major concentration that $\mathbf{T}$.

Table 2. Determination of $\mathbf{A}$ and $\mathbf{T}$ in mixtures with different mass ratio.

\begin{tabular}{|c|c|c|c|c|}
\hline & \multicolumn{2}{|c|}{ Mass added (mg) } & \multicolumn{2}{c|}{ Mass found (mg) (recovery, \%) ${ }^{\mathrm{a}}$} \\
\hline & & & & $\mathbf{A}$ \\
\hline $\begin{array}{c}\mathbf{A} / \mathbf{T} \\
\text { Molar ratio }\end{array}$ & $\mathbf{A}$ & $\mathbf{T}$ & & $\mathbf{T}$ \\
\hline & & & & \\
\hline $17 / 1$ & 25.8 & 3.0 & $24.8(96.1 \pm 1.9)$ & $3.0(100.0 \pm 1.9)$ \\
\hline $34 / 2$ & 51.6 & 6.0 & $49.7(96.4 \pm 1.9)$ & $6.0(100.0 \pm 1.8)$ \\
\hline $51 / 3$ & 77.4 & 9.0 & $75.4(97.4 \pm 1.8)$ & $9.0(100.0 \pm 1.5)$ \\
\hline
\end{tabular}

${ }^{a}$ Average of five determinations.

The excipients contained in this tablet are known but its proportion is confidential. In this context, an study about the effect of the excipients on the proposed method was carried out by adding $10.0 \mathrm{mg}$ of each excipient of this drug; croscarmellose sodium, estearic acid, cellulose, glyceryl behenate, hypromelose, titanium dioxide, polyethylene glycol (PEG), polysorbate, FD\&C yellow \# 5 lake and povidone, in a mixture that contain, $2.0 \times 10^{-5}$ and $34.0 \times 10^{-5} \mathrm{~mol} / \mathrm{L}$ of $\mathbf{A}$ and $\mathbf{T}$, respectively. The recoveries were found 97.4 $\pm 2.0 \%$ and $100.6 \pm 1.7 \%$ for $\mathbf{A}$ and $\mathbf{T}$, respectively. From these results it is possible to establish that the excipients of this tablet do not interfere in the proposed method.

Application of the proposed method

The proposed method was applied for the $\mathbf{A}$ and $\mathbf{T}$ determination in $\mathrm{Zafin}{ }^{\circledR}$, a pharmaceutical elaborated by Laboratorio Saval S.A., Santiago, Chile. This pharmaceutical formulation has an average weight of $459.8 \mathrm{mg}$ containing nominally $325.0 \mathrm{mg}$ of $\mathbf{A}$ and $37.5 \mathrm{mg}$ of $\mathbf{T}$. When the proposed method was used it was found a content of $324.4 \pm 4.1 \mathrm{mg}$ and $38.0 \pm 0.1 \mathrm{mg}$ for $\mathbf{A}$ and $\mathbf{T}$, respectively.

\section{CONCLUSIONS}

Although in the pharmaceutical formulation $\mathbf{A}$ and $\mathbf{T}$ are present in a $17 / 1$ molar ratio, it was possible the simultaneously determination of $\mathbf{A}$ and T without previous separation by second derivative spectrophotometry. The proposed method was applied successfully in synthetic and real samples. Recovery values obtained for $\mathbf{A}$ and $\mathbf{T}$ were in the range $97.4 \pm 2.0 \%$ and 100.6 $\pm 1.7 \%$ for $\mathbf{A}$ and $\mathbf{T}$, respectively, which demonstrates the applicability of the method in real samples and indicates that is essentially free of interference when applied to the analysis of the pharmaceutical formulations. The detection limits for $\mathbf{A}$ and $\mathbf{T}$ were $2.4 \times 10^{-7}$ and $1.0 \times 10^{-7} \mathrm{~mol} / \mathrm{L}$, respectively. This method is recommended for routine and quality control analysis in pharmaceutical industry.

\section{ACKNOWLEDGEMENTS}

The authors are grateful to the National Fund for Development of Sciences and Technology (FONDECYT), project 1070905 and DIUC project $\mathrm{N}^{\circ}$ 204021021-1 for the financial support and to Laboratorio Saval S.A. Santiago, Chile, for his help providing acetaminophen and tramadol.

\section{REFERENCES}

1. Raffa RB, Nayak RK, Liao S.\&, Minn F.L., Rev Contemp. Pharmacother.485-97 (1995)

2. Filitz J., Ihmsen H., Günther W., Tröster A., Schwilden H., Schüttler J.\& Koppert W., Pain, doi:10.1016/j.pain.2007.06.036 (2007)

3. Perrot, S., Krause, D., Crozes, P., \& Naïm, C. Clin. Ther. 28, 1592, (2006).

4. McClellan, K., \& Scott, L.J. Drugs. 63, 1079, (2003).

5. Schnitzer, T. Eur. J. Anaesth. 20, 13, (2003).

6. Kucuk, A., Kadioglu, Y., \& Celebi, F. J. Chromatogr. B. 816, 203, (2005).

7. Sha, Y.F., Shen, S., \& Duan G.L. J. Pharm. Biomed. Anal. 37, 143, (2005).

8. Freeman R., Raskin P. \& Hewitt DJ, Current Medical Research and Opinion 23 (1): 147 (2007).

9. Filitz J. et al. Pain, doi: 10.1016/ j. pain. 2007.06.036. (2007).

10. Espinosa, M., Ruiz, A.J., Sánchez, F., \& Bosch, C. J. Pharm. Biomed. Anal. 42, 291 (2006).

11. Kucuk, A., \& Kadioglu, Y. Il Farmaco. 60, 163 (2005).

12. Gan, S., Ismail, R., Wan, W.A., \& WanAdnan, Z. J. Chromatogr. B 772, 123, (2002).

13. Zaghloul, I.Y., \& Radwan, M.A. J. Liq. Chrom. Rel. Technol. 20, 779, (1997).

14. Overbeck, P., \& Blaschke, G. J. Chromatogr.B 732, 185, (1999).

15. Nobilis, M., Kopecky, J., Kvetina, J., Chladek, J., Svoboda, Z., Vorisek, V., Perlik, F., Pour, M., \& Kunes, J. J. Chromatogr. A 949, 11, (2002).

16. Valle, M., Pavon, J.M., Calvo, R., Campanero, M.A., \& Troconiz, I.F. J. Chromatogr. B 724, 83, (1999).

17. Ho, S., Wang, J.J., Liaw, W.J., Ho, C.M., \& Li, J.H. J. Chromatogr. B 736, 89, (1999).

18. Gambaro, V., Benvenuti, C., Ferrari, L., Dell Acqua, L., \& Fare F. Il Farmaco 58, 947, (2003).

19. Hadidi, A.K., Almasad, K.J., Al-Nsour, T., \& Abu-Ragheib S. Forensic Sci. Int. 135, 129, (2003).

20. Uhl, M. Forensic Sci. Int. 84, 281, (1997).

21. Soetebeer, U.B., Schierenberg, M.O., Schulz, H., Gr"unefeld, G., Andresen, P.,\& Blaschke, G. J. Chromatogr. B 745, 271, (2000).

22. Abdellatef, H.E. J. Pharm. Biomed. Anal. 29, 835 (2002).

23. Li, Y., Wan, X., \& Wang, G. J. Pharm. Chinese-Beijing. 41, 1594, (2006).

24. Zhu, T., Ding, L., Guo, X., Yang, L., \& Wen. A. Chromatographia. 66, 171, (2007).

25. Savitzky, G., \& Golay M. Anal. Chem. 36, 1627, (1964).

26. Validation of Analytical Procedures: Methodology, International Conference on Harmonization of Technical Requirements for Registration of Pharmaceuticals for Human Use, Geneva, Switzerland. ICH Q2B (1997). 
J. Chil. Chem. Soc., 53, № 2 (2008) 